\title{
Whole-Body Vibration Training InCREASES Vertical Jump Height in a Dance Population
}

\author{
Matthew Wyon, Danielle Guinan, and Adam Hawkey \\ Research Center for Sport, Exercise and Performance, School of Sport, Performing Arts and Leisure, University of \\ Wolverhampton, United Kingdom
}

\begin{abstract}
Wyon, M, Guinan, D, and Hawkey, A. Whole-body vibration training increases vertical jump height in a dance population. J Strength Cond Res 24(3): 866-870, 2010-Whole-body vibration (WBV) training has gained popularity with the strength and conditioning environment. Previous research reported improvements in strength and power after WBV interventions in untrained individuals with little hypertrophical development of the muscles, suggesting that the improvements are because of neuromuscular adaptations. The present intervention study recruited moderately trained individuals that have jumping as integral to their training. Participants were randomly allocated to an intervention or control group. The intervention group was exposed to WBV at $35 \mathrm{~Hz}$ for 5 minutes twice a week, whereas the control group was exposed to a similar isometric contraction stress. Results indicated that after a 6-week intervention, vertical jump height increased significantly $(p<0.05)$ in the intervention group than in the control group. The study concluded that WBV was able to maintain vertical jump height with very little intervention time (10 minutes a week) and therefore should be considered as an intervention form for maintaining jump performance.
\end{abstract}

KEY WoRDS vertical jump, dance performance, vibration, power

\section{INTRODUCTION}

$\mathrm{T}$ he use of vibration training is a topic that has received a lot of attention in recent years for the different effects it can have on the body. It has been used in both the medical and exercise arenas for widely differing reasons; the medical profession has used vibration to treat illnesses such as osteoporosis, and kidneys stones (9), and therapists have been known to use vibration as a method of improving postural control and mobility in multiple sclerosis patients (25). In exercise science, its potential as an intervention strategy for training adaptations

Address correspondence to Dr. Matthew Wyon, m.wyon@wlv.ac.uk.

24(3)/866-870

Journal of Strength and Conditioning Research

(C) 2010 National Strength and Conditioning Association has led to a number of studies focusing upon whole-body vibration (WBV) and resulting in physiological (strength, power, and flexibility) gains $(4,9)$. Research has also shown negative effects from vibration (4), although these are the type that are encountered on a regular basis, for example, when driving our cars or operating machinery with motorized parts (9). However, to cause bodily damage, the exposure needed to be prolonged, for example, chain-saw users have reported tingling numbness and mild pain after 2,000 hours of use, circulatory dysfunctions after 2,000-5,000 hours, and exposure of more than 8,000 hours caused several organic forms of function or organic changes, for example, vertigo, irritability, sleeplessness, and other autonomic disturbances (20).

Whole-body vibration is a simple, low-impact method of exercise $(9,16)$. Because the only piece of equipment required for WBV is a vibration platform, it has become popular with fitness centers around the world (7). The majority of platforms create a sinusoidal vertical vibration, with adjustable frequency and amplitude most commonly using a frequency range of $15-60 \mathrm{~Hz}$ and an amplitude range of 1-15 $\mathrm{mm}$ (4). Work by Mester et al. (17) noted that frequencies from 20 to $30 \mathrm{~Hz}$ elicited the greatest gains in flexibility and strength, whereas frequencies closer to $40 \mathrm{~Hz}$ saw no significantly greater gains.

The physical performance improvements are generally increases in muscular strength and flexibility (16). It is thought that these are elicited through stimulation of neuromuscular pathways and muscle spindles (16). Vibration stimulates the primary endings of the muscle spindle (Ia. afferent), which excites the motor neurons, causing contraction of homonymous motor units, resulting in a tonic contraction of the muscle known as tonic vibration reflex (17). Furthermore, Mester et al. (17) state that the tonic contraction can improve maximum voluntary contraction of muscles, especially when used in conjunction with a standard strength training program. Another study has hypothesized that these improvements are because of motor-unit synchronization and the recruitment of previously inactive motor units (6). The reported increases in flexibility are potentially because of activation of both the stretch reflex and the Hoffman reflex. This is referred to as the vibration paradox, a presynaptic inhibition of the Ia.

866 Journal of Strength and Conditioning Research 
afferent muscle spindle, which permits excitation of the pathways relating to vibration and creates inhibition in the pathways responding to stretch, allowing muscle to stretch further (8).

A number of studies $(3,19,22)$ have examined the acute effects of vibration exposure and have reported improved lower body power indices after participants had been exposed to frequencies of $26 \mathrm{~Hz}$ with amplitudes between 1 and $4 \mathrm{~mm}$ and exposure times between 10 minutes and voluntary cessation. However, it should be noted that when participants were tested immediately after their exposure (21) and if the duration of the exposure was short (4 minutes) (26), performance decreased significantly.

There have been a number of short-term cumulative effect studies $(6,2,15,18)$, which used short time periods of multiple WBV training (10 days to 6 weeks). Bosco et al. (2) found significant improvements in jump performance after a 10-day intervention of performing squats on a vibrating platform, whereas Lieberman and Issurin (15) and Mester et al. (18) all noted improved muscular performances after a 3-week intervention.

The aim of the present study was to examine the effect of a 6-week vibration intervention on vertical jump performance in moderately trained undergraduate female dance students. The participant group was selected for 2 reasons: Firstly, they were moderately trained but did not partake in any formalized resistant training activities and secondly, to see whether vibration training had any extra effect on a population that has jumping as central to its exercise form (32). Ethical approval for the study was granted by the Research Centre for Sport, Exercise, and Performance at the University of Wolverhampton.

\section{Methods}

\section{Experimental Approach to the Problem}

This study was designed to investigate the changes in vertical jump caused by exposure to WBV training over a 6 -week period. Little research has been carried out on the effects of WBV on firstly, moderately trained individuals and secondly, individuals for whom jumping is an integral part of their training regimen. The study also tried to emulate a realistic training exposure by limiting the sessions to 2 a week; previous longitudinal studies had used 3 exposures a week, but for a dance population, this is unrealistic (32). Therefore, a test-retest experimental design was chosen with intervention and control groups.

\section{Subjects}

The participants (Table 1) were 18 female undergraduate dance majors in their last year of a 3-year full-time course and were dancing for 12-16 hours per week (2 technique classes and 5 rehearsals). The study took place during the spring term to avoid examination and performance complications. They were randomly assigned to either the intervention or control group. All participants were on the mini-birth control pill, and they started their menstrual cycle within a 3-4 day period.

\section{Procedures}

The participants were informed of the experimental risks and signed an informed consent form before their involvement. They were tested twice; before and at the end of a 6-week intervention period. A series of anthropometric tests were carried out on each participant, which included skinfolds, girth measurements, height, and body mass. The skinfolds were taken at 2 sites, thigh and calf, following the British Association of Sport and Exercise Science guidelines (28), the mean value for each site was taken and recorded. Girth measurements were taken at the midpoint of the thigh and widest part of the calf; the position of each measurement was recorded for each participant to reduce retest error. Hydration status of each participant was measured by urine specific gravity (Palm Abbe Human Urine Refractometer, Misco, Cleveland, USA).

Each participant undertook a uniform warm-up before completing 3 vertical jumps. The warm-up consisted of 5 minutes on an $\mathrm{x}$-trainer maintaining their heart rate between 120 and $140 \mathrm{~b} \cdot \mathrm{min}^{-1}$, followed by 2 minutes of lower limb dynamic stretching. After a 2-minute rest, the participants

TABLE 1. Participant data.
\begin{tabular}{lrrr} 
& & \\
& Age $(\mathrm{y})$ & Height $(\mathrm{cm})$ & Weight $(\mathrm{kg})$ \\
\hline Intervention group $(n=9)$ & $19+0.78$ & $161.3+5.18$ & $58.9+7.12$ \\
Control group $(n=9)$ & $21.1+0.67$ & $159.9+8.37$ & $57.1+8.16$ \\
\hline
\end{tabular}

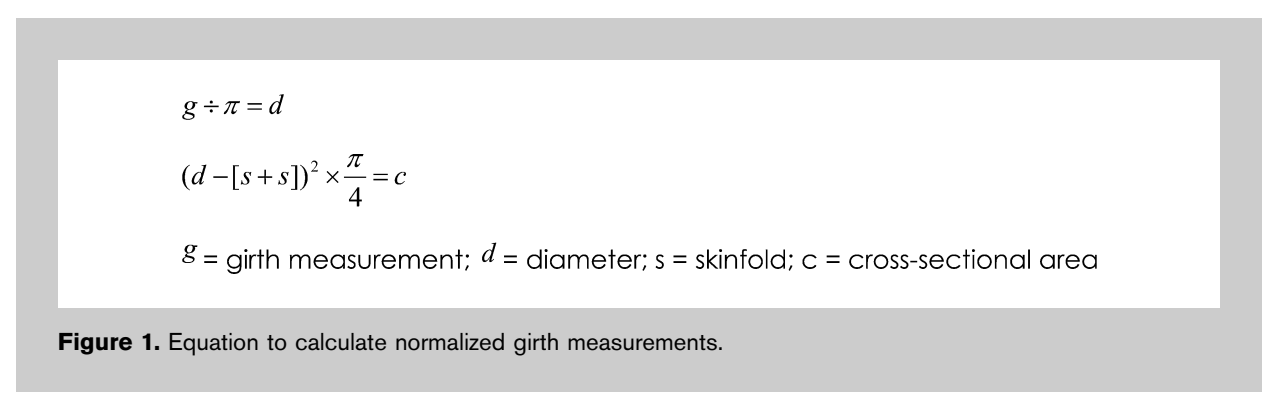


TABLE 2. Summarized data.

\begin{tabular}{|c|c|c|c|c|c|c|}
\hline & \multicolumn{2}{|c|}{ Vertical jump (cm) } & \multicolumn{2}{|c|}{$\begin{array}{l}\text { Standardized thigh } \\
\text { circumference }\left(\mathrm{cm}^{2}\right)\end{array}$} & \multicolumn{2}{|c|}{$\begin{array}{c}\text { Standardized calf } \\
\text { circumference }\left(\mathrm{cm}^{2}\right)\end{array}$} \\
\hline & Pre & Post & Pre & Post & Pre & Post \\
\hline Intervention & $38.8+1.94$ & $41.1+2.1$ & $51.8+4.75$ & $53.3+4.68$ & $34.9+2.85$ & $36.3+2.22$ \\
\hline Control & $36.3+6.71$ & $34.8+6.21$ & $50.4+3.22$ & $51.3+3.0$ & $34.8+2.87$ & $35.4+2.59$ \\
\hline
\end{tabular}

were asked to carry out 3 vertical jumps, using a Just Jump mat (Probotics, Huntsville, AL, USA), which measures air time and calculates jump height from these data. These were carried out with the feet "turned out" in classical ballet's first position and arms remaining stationary in front of the body in "bra-ba." This was to make the jumps as dance specific as possible and remove the effect of arm action on force generation. The highest jump of the 3 attempts was recorded. of muscle cross-sectional area. The vertical jump height and thigh and calf girth measurements were compared pre and postintervention for both the intervention and control groups using multiple factorial analysis (alpha set at $>95 \%$ ).

\section{Results}

There was no significant difference between the group preintervention for hydration status, VJ or anthropometric

\section{Intervention}

The intervention group carried out 2 sessions a week for 6 weeks of static-position vibration training with 2 rest days between the sessions. They held each position twice for 30 seconds at a frequency of $35 \mathrm{~Hz}$ and amplitude of $4 \mathrm{~mm}$. The positions were demi-plié in first position, right leg leading lunge (with just the front foot on the platform), left leg leading lunge, high toe raise (maximal plantar flexion), and bent over hamstring hold (legs remained straight and the torso bent over from the waist more than $90^{\circ}$-similar to the start position of a straight leg dead lift). The control group carried out the same intervention (static holds) but without the vibration stimulus.

\section{Statistical Analyses}

Thigh and calf circumferences were standardized using the equation in Figure 1; this removes skinfold thickness from the girth measurement to provide a more accurate estimation

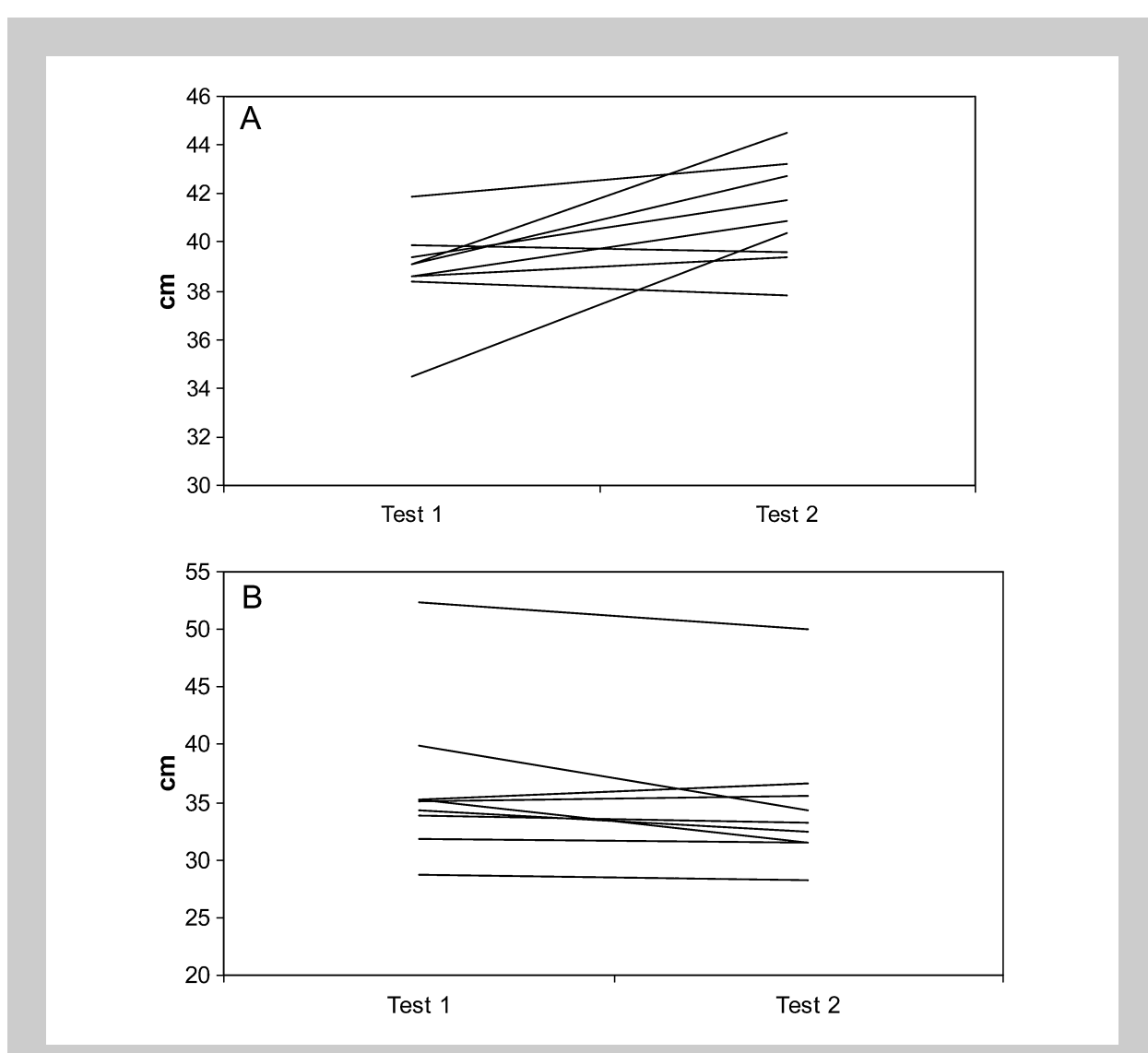

Figure 2. (A) Vertical jump performance for the intervention group and (B) vertical jump performance for the control group.

868 Journal of Strength and Conditioning Research 
measurements (Box' test of Equality of Covariance indicated homogeneity between the groups) though postintervention a significant difference was noted for $\mathrm{VJ}(F(1,32)=7.69$; $p<0.01)$. Analysis by group revealed a significant increase in jump height for the intervention group compared with the control group over the intervention period $(F(1,32)=3.046$; $p<0.05$; intercorrelation coefficient (ICC) $=0.872$ ) (Table 2 and Figure 2). There were no significant changes $(p>0.05)$ in the anthropometric or hydration data for either group over the intervention period $(p>0.05)$.

\section{Discussion}

The reported data in the present study suggest that WBV training has a beneficial effect on vertical jump height compared with age- and skill-matched controls. These results are similar to previous short time period intervention studies $(2,6,16,18)$, though they had differing intervention time periods and exposures. Issurin (5) suggested that these changes are because of a possible number of neuromuscular adaptations; excitation of the primary endings of the muscle spindles that stimulate increased discharge of $\alpha$-motorneurons, and the activation of the Golgi tendon organs whose activation reduces inhibition of muscle action; the similarity of biological mechanisms and vibration training (2) or recruitment of high-threshold motor units (21). The present study suggests that limited exposure to WBV $\left(2 \times 5 \mathrm{~min} \cdot \mathrm{wk}^{-1}\right)$ provides enough stimulation for adaptation to occur in the present population. The possible reasons for this are that although dancers carry out a lot of jumping as part of their training (0.2-0.9 jumps per minute (29) and performances (1-5 jumps per minute $(1,27)$ few undertake supplemental fitness training that is likely to cause physiological adaptation $(10-14,30,31,33)$. Research by Koutedakis et al. (12) and Wyon (33) highlighted the often overtrained status of dancers and the difficulty of implementing supplemental training into their present regimes. The present study has shown that minimal intervention $\left(2 \times 5 \mathrm{~min} \cdot \mathrm{wk}^{-1} \mathrm{WBV}\right.$ training) can have beneficial results that are unlikely to increase the overall training load on the dancers. Further research is now needed to establish optimum frequency, duration, and amplitude levels and long-term effects of vibration training and its interaction with other training methods. Also, the mechanisms for this improvement need to be further examined as there has been no research to date that has investigated the effect of WBV at a cellular level.

Whole-body vibration training can significantly increase vertical jump height in moderately trained participants compared with a similar exposure to isometric resistance. The present study has shown that limited exposure to WBV $\left(2 \times 5 \mathrm{~min} \cdot \mathrm{wk}^{-1}\right)$ is enough to cause adaptation, which is less than previously reported.

\section{Practical Applications}

The results from the present study suggest that exposure to 2 5-minute WBV training sessions a week, for a 6-week period, is sufficient to increase vertical jump height. When combined with previous research reporting that WBV also has a beneficial effect on bone mineral density $(23,24)$, it is recommended that dancers incorporate vibration training into their weekly schedules to not only improve their lower body power indices but also as a preventative measure in maintaining bone mineral density (BMD) (dancers have been reported to have very low BMD (11).

\section{ACKNOWLedGments}

The authors would like to thank the Arts and Humanities Research Council, United Kingdom, for their financial contribution that allowed the research to proceed.

\section{REFERENCES}

1. Angioi, M, Twitchett, E, Metsios, G, Koutedakis, Y, and Wyon, M. Association between selected fitness parameters and aesthetic competence in contemporary dance. J Dance Med Science 13: 115123, 2009.

2. Bosco, C, Cardinale, M, and Tsarpela, O. The influence of whole body vibration in jumping performance. Biol Sport 15: 157-164, 1998.

3. Bosco, C, Colli, E, Intronini, E, Cardinale, M, Tsarpela, O, Madella, A, Tihanyi, J, and Viru, A. Adaptive response of the human skeletal muscle to vibration exposure. Clin Physiol 19: 183-187, 1999.

4. Carindale, $\mathrm{M}$ and Wakeling, J. Whole body vibration exercise: Are vibrations good for you? Br J Sports Med 39: 585-589, 2005.

5. Issurin, V. Vibrations and their applications in sport. A review. J Sports Med Phys Fitness 45: 324-336, 2005.

6. Issurin, VB and Tenenbaum, G. Acute and residual effect of vibration stimulation on explosive strength in elite and amateur athletes. J Sports Sci 17: 177-182, 1999.

7. Fischbach, A. Fitness Business Pro, in shaky ground. Fitness Business Pro 12-15, 2007.

8. Flieger, J, Karachalios, T, Khaldi, L, Raptou, P, and Lyritis, G, Mechanical stimulation in the form of vibration prevents postmenopausal bone loss in ovariectomized rats. Calcif Tissue Int 63: 510-514, 1998.

9. Jordan, M, Norris, S, Smith, D, and Herzog, W. Vibration training: An overview of the area, training consequences, and future considerations. J Strength Cond Res 19: 459-466, 2005.

10. Koutedakis, Y, Cross, V, and Sharp, NCC. Strength training in male ballet dancers. Impulse 4: 210-217, 1996.

11. Koutedakis, Y and Jamurtas, A. The dancer as a performing athlete: Physiological considerations. Sports Med 34: 651-661, 2004.

12. Koutedakis, Y, Myszkewycz, L, Soulas, D, Papapostolou, V, Sullivan, I, and Sharp, NCC. The effects of rest and subsequent training on selected physiological parameters in professional female classical dancers. Int J Sports Med 20: 379-383, 1999.

13. Koutedakis, Y and Sharp, NCC. Thigh-muscles strength training, dance exercise, dynamometry, and anthropometry in professional ballerinas. J Strength Cond Res 18: 714-718, 2004.

14. Koutedakis, Y, Stavropoulos-Kalinoglou, A, and Metsios, G. The significance of muscular strength in dance. J Dance Med Sci 9: 29-34, 2005.

15. Lieberman, D and Issurin, V. Effort perception during isotonic muscle contractions with superimposed mechanical vibration stimulation. J Hum Mov Stud 32: 171-182, 1997.

16. Luo, J, McNamara, B, and Moran, $\mathrm{K}$. The use of vibration training to enhance muscle strength and power. Review article. Sports Med 35: 23-41, 2005.

17. Mester, J, Kleinöder, $\mathrm{H}$, and Yue, Z. Vibration training: Benefits and risks. J Biomech 39: 1056-1065, 2006. 
18. Mester, J, Spitzenfeil, P, Schwarzer, J, and Seifriz, F. Biological reaction to vibration-implications for sport. J Sci Med Sport 2: 211226, 1999.

19. Mileva, K, Naleen, A, Biswas, S, and Bowtell, J. Acute effects of vibration-like stimulation during knee extension exercises. $\mathrm{Med} S \mathrm{Sc}$ Sports Exer 38: 1317-1328, 2006.

20. Twitchett, E, Angioi, M, Koutedakis, Y, Wyon, M. Video analysis of classical ballet performance. J Dance Med Science 13: 124-128, 2009.

21. Rittweger, J, Beller, G, and Felsenberg, D. Acute physiological effect of exhaustive whole body vibration exercise in man. Clin Physiol 20: 134-142, 2000

22. Rittweger, M, Mutschelknauss, M, and Felsenberg, D. Acute changes in neuromuscular excitability after exhaustive whole body vibration exercise as compared to exhaustion by squatting exercise. Clin Physiol Funct Imag 23: 81-86, 2003.

23. Rubin, C, Turner, A, Bain, S, Mallinckrodt, C, and McLeod, C. Anabolism: Low magnitude signals strengthen long bones. Nature 412: 603-604, 2001.

24. Rubin, $\mathrm{C}, \mathrm{Xu}, \mathrm{G}$, and Judex, $\mathrm{S}$. The anabolic activity of bone tissue, suppressed by disease, is normalised by brief exposure to extremely low-magnitude stimuli. FASEB J 15: 2225-2229, 2001.

25. Schuhfried, O, Mittermaier, C, Jovanovic, T, Pieber, K, and Paternostro-Sluga, T. Effect of whole body vibration in patients with multiple sclerosis: a pilot study. Clin Rehab 19: 834-842, 2005.
26. Torvinen, S, Slevanen, H, Jarvinen, T, Psanen, M, Kontulainen, S, and Kannus, P. Effect of 4-min vertical whole body vibration on muscle and body balance: A randomized cross study. J Sports Med 23: 374379, 2002.

27. Twitchett, E, Angioi, M, Koutedakis, Y, and Wyon, M. Video analysis of classical ballet performance. J Dance Med Sci. In Press.

28. Winter, E. BASES Physiology Testing Guidelines (Vol. 2). London, United Kingdom: Taylor and Francis, 2006.

29. Wyon, M. Cardiorespiratory demands of contemporary dance, in School of Life and Sport Sciences. London, United Kingdom: University of Roehampton Surrey, 2004.

30. Wyon, M. Cardiorespiratory training for dancers. J Dance Med Sci 9: 7-12, 2005.

31. Wyon, M, Allen, N, Angioi, M, Nevill, A, and Twitchett, E. Anthropometric factors affecting vertical jump height in ballet dancers. J Dance Med Sci 10: 106-110, 2006.

32. Wyon, M, Deighan, M, Nevill, A, Doherty, M, Morrison, S, Allen, N, Jobson, S, and George, S. The cardiorespiratory, anthropometric and performance characteristics of an international/national touring ballet company. J Strength Cond Res 21: 389-393, 2007.

33. Wyon, MA. Challenging habit: Planning and preparation, the art of periodisation and optimising performance. In: Not Just Anybody and Soul. Van der Linden, M, ed. Amsterdam, Netherlands: Uitgeveij International Theatre and Film Books. 2004, pp. 66-71. 